\title{
Intensidad de lo Posible, o del sentido y la decisión
}

\section{Intensity of the Possible, or on sense and decision}

\author{
MAX MAUREIRA P. \\ Centro de filosofía clásica alemana (Argentina)
}

Recibido: 11-02-2011

Aprobado definitivamente: 25-02-2011

\section{RESUMEN}

porque somos finitos, porque hay límite, hay sentido. Asimismo, en la medida que precisamente somos, constituyendo tal límite, hay comunidad. Aquello que la configura es el despliegue del sentido. Con lo del sentido, lo que se aborda aquí es la esencia de una misma comunidad, una comunidad sin nombre. En este trabajo se revela la intensidad de su despliegue, en su cierre (Schmitt) y apertura (Derrida)

\section{PALABRAS CLAVE}

SENTIDO, FINITUD, DECISIÓN, SCHMITT, DERRIDA

\begin{abstract}
Because we are finite, because there is limit, there is sense. Likewise, insofar as we are precisely, constituting such limit, there is community. It is the display of sense what forms it. With the sense issue, what we approach here is the essence of a community itself, a community without name. In this work we disclose the intensity of its display, in its closing (Schmitt) and opening
\end{abstract} (Derrida).

\section{KEYWORDS}

SENSE, FINITENESS, DECISION, SCHMITT, DERRIDA

(C) Contrastes. Revista Internacional de Filosofia, vol. XVII (2012), pp. 197-212. ISSN: 1136-4076

Departamento de Filosofía, Universidad de Málaga, Facultad de Filosofía y Letras Campus de Teatinos, E-29071 Málaga (España) 
Según Kant, CONOCER Algo eXIGE unA RElación CON un OBJeto, cuyo significado y sentido quedan más allá de él, es decir, allende lo que conforme a la misma relación se concibe como real. Si no fuera así, advierte Kant, o sea, si no hubiera tal referencia, no habría más que conceptos vacíos. ${ }^{1}$ Con lo cual, el ámbito de la realidad objetiva, de la experiencia, se vincula con el del significado y el sentido a priori. Que el ámbito en el que se decide el significado y el sentido de la experiencia quede mas allá de ella, sugiere entonces que, en lo que sea que éste consista, es a priori, vale decir, no corresponde a su esfera, sino queda allende la misma. O, dicho todavía de otro modo, la experiencia recibe su significado y su sentido, a saber, aquello en lo que consiste, desde este más allá.

Cuando Dilthey, años más tarde, y por otra parte, aborda la historia, esta comprensión kantiana es la que sigue resonando cuando afirma que ninguna palabra propia de la misma historia puede expresar «su sentido verdadero». ${ }^{2}$ Con esto Dilthey sugiere algo más, en lo que Kant no se detenía mayormente: no hay un único sentido. Así como a un objeto corresponde un sentido, así también a la historia, pero este sentido no es uno. Ya se sabe que Nietzsche saca luego las conclusiones de esto, siguiendo más bien a Schopenhauer, v. gr. radicalizando la pregunta por el sentido mismo, convirtiéndolo en lo que hasta él no era: un asunto. ${ }^{3}$

Ahora, a este asunto o cuestión inaugurada por el sentido le es propio, pese a su referencia a un más allá, realizarse en un más acá. Con ello se insinúa de entrada una mediación: la del lenguaje. Aquello que desde el más allá da sentido, lo da, se realiza como tal, en y mediante el lenguaje. Pero siendo así, cuando el sentido se transforma en un significado cognoscitivo, lo más allá se disuelve en mero significado. Luego, no parece que el sentido, que el más allá, se pueda escapar a la totalidad que supone el lenguaje. Si él es propio de aquí, del más acá, entonces parece que, en rigor, ya no hay más allá. Wittgenstein coincide con esto cuando se refiere al sentido del mundo. Si ha de haber sentido, afirma, se ha de encontrar fuera de la totalidad que el mundo supone, a saber, la de los hechos ${ }^{4}$ o, se podría decir también, la del lenguaje. Con lo dicho es suficiente para poner en evidencia el poder de este último, que puede sacar a la luz el

1 Cf. I. Kant, Kritik der reinen Vernunft. Hamburgo: Meiner, 2003, p. B 194.

2 Cf. W. Dilthey, Gesammelte Schriften, I. Berlín-Leipzig: Teubner, 1922, p. 99.

3 Por cierto, la cuestión con la que enlaza Nietzsche, y que es sugerida por Schopenhauer, no se refiere al sentido en general, tampoco al propio de la vida, sino, y más preciso, al de la existencia (Dasein). Cf. F. Nietzsche, Werke, II. Munich, Hanser, 1973, p. 228.

4 Ya en la primera proposición del Tractatus se lee que «el mundo es todo lo que es el caso» (1), o que aquello que lo constituye es «la totalidad de los hechos, no de las cosas» (1.1.). No obstante, agrega Wittgenstein, «el sentido del mundo tiene que estar fuera de él [del mundo]» (6.41). Cf. L. Wittgenstein, Tractatus logico-philosophicus. Frankfurt/M: Suhrkamp, 1963. 
sentido, traer a la presencia lo escondido más allá del lenguaje y, no obstante, al mismo tiempo, hacerlo añicos. Porque, efectivamente, y tal como se ha sugerido, al convertirse el más allá en lenguaje, al resultar mediado por éste, ya no hay ni allá, ni acá, es decir, no hay otro mundo, sino que el mundo es uno, el del lenguaje. A él se remite la totalidad de sentido. Por lo tanto, aquello que no se puede decir, que no se puede reducir a él, no es nada que quede fuera del mundo, sino acaso, como llega a considerar Hegel, y sencillamente, no es real o racional, ${ }^{5}$ afirmación que ha de entenderse advirtiendo que aquí mundo, razón y lenguaje refieren el mismo lugar común. En suma, si sólo hay un mundo, y si aquello que lo configura es el lenguaje, entonces la cuestión por el sentido sólo parece tener que desentrañarse aquí dentro.

Aun así, Wittgenstein insiste en esto contra Hegel, a saber: aquello sobre lo que se ha de callar, no es porque suponga un sinsentido, esto es, porque sea irracional. Lo sin palabras, afirma él, en verdad no tiene ninguna relación, ni con lo irracional, ni con lo racional. Aquello impronunciable, esto que se viene refiriendo aquí como sentido, ocurre que, simplemente, está más allá de la frontera de lo pronunciable. A esto, a lo que queda más allá del lenguaje, fuera por tanto de la razón, de su mediación, fuera del mundo, es a lo que apunta Wittgenstein. Para referirse a ello de algún modo, le llama así: lo místico. ${ }^{6}$

Al hablar, el hombre crea, tiene el poder de crear, da nombres, nombra esto y lo otro, construyendo un reino, un mundo, el del lenguaje, que supera lo sensible. Por esto no se trata aquí de un mero poder entre otros, sino, como se ha insinuado, y considera Hegel, del poder «supremo entre los hombres».? No obstante, y de nuevo, según Wittgenstein siempre hay algo más allá, algo innombrable, místico, algo no sujeto a la mediación que entraña el lenguaje.

A pesar de esto, por medio del lenguaje se realiza tal más allá; es, tiene lugar, en y como lenguaje. He aquí lo importante. Pues bien, a resultas de esto, la realización del habla, en la medida en que tiene lugar, constituye una historia, la suya. Antes de volver al sentido, al más allá, detengámonos su realización. Cada lengua dice o expresa algo, siendo así que lo dicho, pero también el decir mismo, significa, tiene significado, por consiguiente, está en relación. Luego, lo realizado en el lenguaje no es más que la mediación concreta. Benjamin, quien

5 O, como anota él mismo: «todo lo que es racional es real, y lo que es racional es real». Aquello que constituye la realidad es aquí lo racional. $C f$. G.W.F Hegel, Werke, VII. Frankfurt/M: Suhrkamp, 1970, p. 24. Sobre lo constitutivo de la realidad, ya había advertido también Fichte, sólo que en lugar de la razón él sugiere que es la libertad. Cf. J. Fichte, Gesamtausgabe, IV, 2. Stuttgart: Fromann-Holzboog, 1978, p. 24. Como sea, no hay más allá de la realidad; lo racional o lo libre es en lo que ella consiste.

$6 C f$. L. Wittgenstein, op. cit., proposición 6.522.

7 G.W.F Hegel,.Werke, op. cit., IV, p. 52. 
considera la historia de este modo, sostiene que al lenguaje, configurador de la misma, le es propio, sin embargo, al igual que a ella, un estadio último en el que se supera esta constitutiva mediación, es decir, en el que se disuelve toda referencia, toda relación, para que el lenguaje, en definitiva, no comunique nada más que a sí mismo. ${ }^{8}$ Aquello que se revela en el lenguaje, esto es lo sugerido, descansa, por consiguiente, en una revelación que da sentido al mismo. Por medio suyo, él tiene lugar en la historia. Benjamin refiere esta esfera trascendente de una manera similar a la propia de la religión. ${ }^{9}$

Si la experiencia, el lenguaje o la historia adquieren todo su sentido en esta remisión más allá de sus esferas, entonces, desde dónde ellas se proyectan es lo que queda en el centro de toda pregunta por el sentido. Ante todo, ¿qué frontera es ésta?, ¿qué es lo que se abre y cierra con el sentido? A decir de Kant, para volver a él, la experiencia misma es la frontera: hay un más allá de ella; como también, se podría agregar, un más allá de la historia, que según Dilthey y Benjamin no se puede expresar. $\mathrm{Si}$, como advierte Nietzsche, en verdad no se trata de una sola frontera, sino de varias, de nuevo: ¿qué abre y cierra cada una, en el entendido que ello es posible porque existe algo común a las mismas?, ¿acaso el lenguaje, ese entramado de recíprocas referencias infinitas? Pero, ¿hay algo fuera de él?, por ejemplo, ¿algo místico o perteneciente a la religión, algo que escape a la mediación y que, así, quede más allá de las fronteras que ella supone? A partir de lo revisado hasta aquí, se puede preguntar esto todavía de otra forma: ¿hay algún lenguaje que no diga absolutamente nada, que no suponga ninguna mediación, ni, por consiguiente, según Benjamin, la necesidad de traducir, sino uno que, nada más, hable; hable sin presuponer ninguna lengua, y por lo tanto sin ninguna referencia que no sea a él mismo, o sea, a su propia habla?

\section{COMUNIDAD DE FRONTERAS}

Aquí, más acá, ocurre que estamos, que somos con los demás, es decir, que cada uno no está solo, por ello este estar es siempre un co-estar con el resto, cuestión que no es una trivialidad, ni menos un mero accidente, sino que es consustancial a nuestra existencia. ${ }^{10}$ Ahora, a este co-ser le es propio dejarse decir sólo en la distinción, vale decir: uno es tal o cual en la limitación o, expresado de otra forma, uno es uno en la medida en que no es otro. Bien, con esto se sugiere que quién sea uno, no se da sin más, sino que tiene lugar a partir

8 Cf. W. Benjamin, Sprache und Geschichte. Philosophische Essays. Stuttgart: Reklam, 2010 , p. 31

$9 C f$. Benjamin, Walter, ibid, p. 37.

10 Uno de quienes han llamado la atención con mayor énfasis sobre esto, interpretando a Heidegger, es Nancy. Cf. J-L. Nancy, Etre singulier pluriel. París: Galilée, 1996, pp. 45-46 y 82-83. 
de un conjunto de posibilidades que se van configurando materialmente. Por lo tanto: éste o aquél es en base a un conjunto de ellas, realizadas como tales. Lo que constituye esencialmente a cada uno es entonces un límite. En la medida en que delimito estas posibilidades, soy éste o aquél. No obstante, que sea este tal, no impide que devenga tal otro, porque lo propio de este límite es la movilidad, el cambio constante. ${ }^{11}$ Pero entonces, justamente el límite, el umbral, la frontera mediante la que uno se distingue en cuanto tal, siempre queda atrás, es decir, aparece desapareciendo. A nuestra finitud le es propia esta característica. Ocurre, sin embargo, que cuando el límite en que consiste tal finitud se vuelve un asunto, suele ser para decir sólo la distinción de la misma finitud, o sea, la distinción en virtud de la cual soy, eres, él o ella son.

Que uno sea éste o aquél supone una distancia, y a saber, determinada por el límite que configura la distinción entre ambos. Como soy finito, soy según el límite que esta finitud entraña. Al concebirme de un modo u otro, sucede entonces que no sólo configuro mi límite, sino que además, y como se ha advertido, éste desaparece como tal. En consecuencia, en qué consista el límite, no es nunca lo inmediato. Así pues, quién sea uno está siempre en relación con alguien que no soy, es decir, y en suma, por referencia a un más allá del límite que soy yo. Cada vez hay relación, cierto, pero ella, como tal, se comprende sólo desde lo distinguido. Como esta experiencia del límite es propia de la relación con los demás, no sólo hay límite de mí respecto al resto, sino también, colectivamente, de unos respecto a otros. Volvamos a lo ya advertido: al comparecer con el resto, uno lo hace hablando, ya que lo propio del congregarse de los hombres es que ocurra mediante el lenguaje. ${ }^{12}$ Quién sea uno, pues, acontece por una parte, en la finitud y, por otra, en el lenguaje, en la mediación, es decir, en la relación que, intrínsecamente, se supone respecto a quienes, como yo, son finitos.

Con este estar y ser cada uno en relación con, es decir, con este estar vuelto siempre, y de modo constitutivo, más allá del límite que supone toda finitud, se relaciona ya no sólo el lenguaje o su quehacer constitutivo en la historia, sino, sobre todo, algo ya referido: el sentido. Cabe preguntar entonces: ¿cómo exactamente? Con lo dicho hasta aquí, está claro que quién sea uno se da en relación con los demás, pues lo constitutivo del límite se entiende a partir de tal relación. $\mathrm{O}$, en otras palabras, uno es el límite que se configura interactivamente, a saber, mediante una corelacionalidad singular a la que en conjunto se llama mundo. Cuando Wittgenstein se refiere al sentido, lo que mienta con este más allá del mundo no es, por lo tanto, ningún lugar inaccesible, sino lo que, apare-

11 Pues, como lo expresa Pascal: «nuestra naturaleza está en el movimiento: el reposo completo es la muerte». Cf. Pascal, Pensées. Gallimard, París, 1998-1999, II, 129.

12 Sobre esto, M. Maureira, «Ethos y lenguaje. A propósito del habla en Aristóteles», Philosophia, 66/67 (2006-2007), pp. 87-98. 
ciendo, precisamente como mundo, v. gr. finitamente, desaparece: el sentido. Si los límites, por ende, son constitutivos de nuestra finitud, y si el sentido no es más que la realización finita de este quedar más allá de ellos, entonces parece inevitable la contraposición, el confrontarse con los otros para, precisamente, ser quién se es, para realizarse o tener lugar en un horizonte concreto. Aquello que dirige esta confrontación, al quedar más allá de la determinación, le da, en esta medida, sentido. Así pues, puesto que el qué del límite siempre queda detrás, y porque uno siempre es en relación al resto, v. gr. en el lenguaje, en cuanto ese resto es quién no es uno, hay sentido. Con el sentido, en definitiva, se mienta el límite respecto a la correlación conjunta, es decir, el más allá del mundo. Pues bien, ¿en qué consiste este más allá involucrado en lo que se viene llamando sentido del mundo?

\section{AMIGOS Y ENEMIGOS}

A nuestra finitud, determinada por la muerte, a nuestro saber que vamos a morir, le es propia no sólo el que, a partir de un conjunto de posibilidades, cada uno sea el que es mediante un estarse autolimitando continuo, sino, y más aun, que nada de esto haya de ser así o de otro modo, esto es, que quién sea uno, no es necesario, pues lo esencial, bien visto, es más bien al contrario. Ahora bien, que lo constitutivo de los hombres sea este poder ser siempre distintos, supone que hay una decisión, es decir, que uno, en la medida en que lo decide, es éste o el otro. $\mathrm{O}$, expresado de otra manera, uno está decidiendo de modo constante, y decide porque, precisamente, lo propio de uno es no tener que ser, sino siempre poder ser. Con lo cual, lo que hace la decisión es delimitar las condiciones conforme a las cuales uno es tal o cual, y por cierto también, en igual medida, la negación de ello, la diferencia, la relación respecto a los que uno no es el que es. Así, consustancial a la finitud es lo posible que entraña toda posibilidad, es decir, el que lo que es, pueda ser siempre, y necesariamente, de otra manera.

Cuando, a resultas de esto, me concibo, no ocurre simplemente entonces que me sé con el resto, esto es, que me sé quién soy con los demás, sino, en virtud de este saber, me interpreto, ergo, me comprendo en esta constitutiva y conjunta remisión. Aquello que se configura en mí es, de este modo, ya no sólo un límite, sino también el acceso a la totalidad a que estoy remitido, es decir, al conjunto de referencias o límites que constituyen conmigo la totalidad..$^{13}$ Con esta interpretación referida al conjunto, lo que se deja ver es la consustancial manera de mirar propia del límite. Así, en ella se está, pero, configurado el límite, ella queda siempre atrás. Quedo dentro de la totalidad y, en este sentido, miro

$13 \mathrm{Al}$ respecto ha llamado la atención Heidegger, resaltando que la referencia al conjunto es la propia del sentido. Cf. M. Heidegger, Sein und Zeit. Tübingen: Max Niemeyer, 2001, p. 151. 
a partir suyo, pero el mirar mismo queda fuera de ella, de forma que cuando interpreto lo hago dejándolo detrás, a saber, asumiendo la mirada desde la que interpreto. A Heidegger corresponde haber considerado esta mirada como lo a priori. Así como la experiencia, la historia o el lenguaje, remiten a un más allá, así ocurre también, según él, con la existencia (Dasein). A diferencia de Kant, no hay un allende la experiencia, concebida ella como totalidad, ni tampoco un más allá de la historia o del lenguaje, sino que el mundo, en cuanto totalidad, es el umbral. Cuando se lo concibe como tal, cuando en definitiva hay mundo, es porque se abre, porque se descubre, a saber, precisamente como mundo, mediante una interpretación. Pues bien, a esta apertura es a lo que Heidegger llama sentido. ${ }^{14}$ Lo que se aclara, lo que se abre, es a través del sentido. Por lo tanto, en qué consiste estar en el mundo, se aclara respecto a esta totalidad. Abierto el mundo mediante el sentido, queda dispuesto a su apropiación.

Ahora bien, a esta totalidad comprensiva le es propia la compartibilidad, a saber, la remisión conjunta, este mi ser con otros en ella, que queda supuesta. Cuando se aborda el sentido, esta vinculante compartibilidad es la que, en efecto, queda atrás. Aunque no la considere, cada interpretación la supone siempre. Que se pueda, nunca que se deba, ser de un modo u otro, quiere decir entonces que se comprende, y esto significa que la totalidad a la que me remito es a aquella en la que me muevo, movimiento que trasluce la constante y contingente determinación concreta, que, a su vez, porque y en la medida en que la comprendo, tiene un sentido. El mundo, pues, no es más que la realización del sentido con los demás, en la relación con ellos de una forma u otra. Por consiguiente, así como lo que se mienta con mundo es una correlación con el resto, así ocurre con el sentido o, quizás habría que decir, con el sentido del sentido. ${ }^{15}$ Pero, ¿en qué se distinguen entonces el mundo del sentido?

Quienes resultan agrupados por un sentido, configuran el mundo, de modo que quien lo conoce, sabe de sus referencias constitutivas, de la totalidad que comprende, pero sabe también, o ha de saber, justamente por esto, que se trata,

14 A propósito de esto, Heidegger llama la atención, «en la medida en que el comprender y la interpretación constituyen la constitución existencial de la existencia»y que «el comprender, en cuanto apertura del ahí, atañe siempre a la totalidad del estar-en-el-mundo», es que «el sentido debe ser concebido como la estructura existencial-formal de la apertura que es propia del comprender». $C f$. M. Heidegger, op. cit., p. 151-152.

15 A esto, el sentido sin más, se refiere Derrida con este término de difícil traducción «différance». Cada momento de lo significado deja siempre atrás lo que el movimiento trae a nuestra presencia, al constituirse este último, consustancialmente, por referencia a algo. Con el término indicado, lo que Derrida tematiza es este traer a la presencia del movimiento mismo. Cf. J. Derrida, Marges de la philosophie. Paris: Éditions de Minuit, 1971, p. 13. A Nancy, precisamente porque tal movimiento siempre queda atrás, no le falta razón para llamarlo sentido del sentido. Cf. J-L., Nancy, Le sens du monde. París: Galilée, 1993, p. 28. 
en todo momento, de una posibilidad. A Carl Schmitt corresponde haber llamado la atención sobre esto. Aquello que decide un sujeto, v. gr. el soberano, es, sugiere Schmitt, la realización del sentido, los términos de la misma. Sin embargo, advierte él, lo constitutivo del sentido mismo queda más allá. Lo que el soberano administra es la realización de la interpretación, sin considerar en qué consista ella, su qué o quididad.

Así pues, congregados en torno a quien decide, o sea, al soberano, lo que se realiza con su disposición no es más que una apertura del mundo. Una decisión configura tal apertura, ella es el umbral o, como se ha indicado anteriormente, el límite. A quienes se congregan más acá de éste, Schmitt los caracteriza como amigos; a los que más allá, como enemigos. Con esto, el límite en cuanto tal, o lo constitutivo de la distinción que arranca por medio suyo, queda atrás, quedando en un primer plano el límite mismo, su realización, su forma y contenido. Lo que puede variar no es el que haya límite, pues constantemente lo hay, sino la intensidad del que sea. ${ }^{16}$ Según Schmitt, hay entonces una realización, debe haberla, esto es, una decisión que acote un límite cualquiera. Pero por cierto, si hay límite, hay distinción. Por tal razón, cada congregación, cada comunidad, puesta a un lado del límite, está llamada a afirmarlo, a apropiárselo, para que precisamente él se dé, con un grado de intensidad en función de su apropiación. Ahora, para volver a lo planteado, si en torno a la cuestión del sentido, no lo que queda delante, sino, en verdad, lo que continuamente queda detrás es lo que importa, ¿qué hay en último término detrás de cada relación, de cada límite, de toda decisión?, ¿acaso lo místico, la religión o incluso Dios?

Cuando Schmitt se refiere a la distinción constitutiva de todo límite, no lo hace para referirse a la política, sino a lo político. Con esto último apunta a lo esencial de la primera. A esta esencia corresponde su característica distinción entre amigos y enemigos. Se es amigo o enemigo siempre en relación con los demás. Por medio de una decisión cualquiera, o más concreto, de una decisión que se pone por encima de otras, lo que se concreta es, de entre un conjunto de posibilidades, una que se antepone a las demás. A la finitud, como se ha indicado, le es propia tal disposición, le es propio decidir, no una vez, sino en todo momento. Si esto es así, si con cada decisión se configura este o aquel otro límite, y por lo tanto, se configura también este amigo o enemigo, la cuestión es: ¿qué es lo constitutivo, ya no de ser amigo o enemigo, sino del hecho que haya unos y otros?

Aquello propio del límite, de todo límite, lo consustancial a él, es lo ya sugerido: una relación, lo entre que ella supone. Así lo refiere Hannah Arendt.

16 Con la famosa distinción constitutiva de lo político, entre amigo-enemigo, Schmitt refiere «el grado de intensidad de una asociación o disociación de hombres». $C f$. C. Schmitt, Der Begriff des Politischen. Berlín: Duncker \& Humblot, 1987, p. 26. 
Pues es entre los hombres que se abre el mundo; él viene a ser, en definitiva, el espacio constituido por ellos. Y por eso, concluye ella, el «punto central de la política es siempre la preocupación por el mundo», ${ }^{17}$ no la por el hombre, cuestión que, en verdad, ya la misma palabra griega sugiere. Con ta politikhe, que sustantiva el adjetivo polítikos, lo que se mienta en griego es vecindad, es decir, este entre al que se refiere Arendt. Antes que a la ciudad, la palabra alude a la relación de los hombres entre sí, a la relación entre los vecinos de la pólis. Cuando Aristóteles la utiliza, ya se sabe que con ella mienta, además, el saber acerca de esto. Sin perjuicio de ello, cuando la relación referida es la de los ciudadanos con la ciudad, y no entre ellos, los griegos utilizan, en cambio, la voz politeia. Quien actúa políticamente, actúa en virtud de la totalidad que tal actuación supone. Para todo griego, ella no es otra que la pólis.

Que esto sea así, es decir, que uno actúe permanentemente en relación con los demás, o sea la vecindad, es algo que, en griego, se debe a nuestra finitud, a la muerte. Cada uno lleva la muerte del otro. Su muerte no es más que la propia. Por eso Derrida afirma que la amistad entre los hombres no es un asunto del presente, sino una promesa asentada en el oír y en el comprender que propicia la vecindad. ${ }^{18}$ Por consiguiente, el otro no es un mero otro que posibilita la propia comprensión, sino que me llama; él es un interlocutor que, en esta medida, me y nos configura. Así pues, la amistad se asienta en este dejar ser al otro. ${ }^{19}$ Sin embargo, porque ello siempre tiene lugar distinguiéndose, la disputa parece inevitable.

Carl Schmitt insiste de acuerdo con ello en la distinción amigo-enemigo como lo esencial de lo político. Ninguna unidad última resulta posible. Aquello que converge en la vecindad de la pólis es, según esto, una relación recíproca en permanente e inevitable distinción y, con ello, en constante disputa. Bien, ocurre que, al hablar, uno se abre a los demás precisamente distinguiéndose de ellos. Derrida insiste por eso que el otro no es más que el vecino, pues a esto se refiere originalmente la politikhe, pudiendo ser luego, por cierto, amigo o enemigo. Con esto deja abierta una transformación posterior de la politikhe. ${ }^{20}$ Con la determinación sugerida por Schmitt, en cambio, no hay ninguna apertura,

17 H. Arendt, Was ist Politik?, Ursula Ludz (ed.). Múnich-Zürich: Piper, 1993, p. 24.

18 En efecto, «la amistad no es nunca algo dado presente, ella forma parte de la experiencia de la espera, de la promesa o del compromiso». $C f$. J. Derrida, Politiques de l'amitié. París: Galilée, 1994, p. 263.

19 A este respecto, en una confrontación de Heidegger con Derrida. Cf. Schramm, Michael, «Politik der Freundschaft. Zur Aristóteles- und Heidegger Rezeption bei Derrida», Internationales Jahrbuch für Hermeneutik, 6 (2007), p. 293.

20 Que se relaciona con el porvenir (à-venir), y no con el futuro, que carece de la apertura original. Cf. J. Derrida, Force de loi. Le «Fondement mystique de l'autorité». París: Galilée, 1994, p. 60. 
sino que la sugerida transformación derrrideana está llamada a concretarse en una unilateral amistad o enemistad. ${ }^{21}$ Así pues, mientras Derrida renuncia a cualquier criterio que permita la distinción entre unos y otros, que no rebase, claro está, la posibilidad de la muerte, de forma que si renuncio a la de mis amigos, afirmo la de mis enemigos, Schmitt sugiere un criterio, que no obstante deja abierto en su determinación concreta. Con una tal determinación, lo que se cerraría es, consumándolo, el criterio de pertenencia a una comunidad. Aquí la cuestión se plantea entonces en términos de si hay un más allá de todo criterio, un criterio del criterio, según el cual uno es amigo o enemigo. Así llegamos de nuevo al más allá que envuelve el sentido.

\section{GUERRA}

A la cuestión del criterio cabe acercarse recordando, en efecto, que con la referencia al más allá y al más acá lo actualizado es el sentido, y esto ha de entenderse aquí del siguiente modo. Cada criterio se remite a un sentido. Que haya $u n$ sentido, sugiere $u n$ mundo en el que se realiza un criterio y que, naturalmente, en el momento en que se determina, ya es uno, es decir, no es sin más, no es el por antonomasia, el puro. Con la devenida remisión a otros que ello supone, pues sólo hay uno si hay más de uno, no hay ningún criterio que escape a tal relación. Puesto que no hay, pues, un criterio del criterio, no hay un afuera de los criterios singulares; ellos están en el mundo en relación unos con otros. A su vez, si el mundo es la realización del sentido, ¿cómo es que se realiza?, ¿cómo se distingue $e l$ sentido de los sentidos o el criterio de los criterios? Al sentido, como se ha revisado, no le es propia la referencia a una singularidad, sino al conjunto. Que con mundo se miente la realización del sentido, quiere decir entonces que lo referido es la remisión al horizonte conjunto en el que se hace comprensible algo, pero no porque subyazca a cada algo, como advierte Heidegger, sino porque con la comprensión de ese conjunto, propia del sentido, lo abierto es el mundo mismo. ${ }^{22}$

Ciertamente, con esta apertura se da, sobreviene, al mismo tiempo un cierre, pues a ella le es propia, en la medida en que se corresponde con la finitud, un límite, o sea: cerrarse. Si, por consiguiente, a cada comprensión le corresponde un sentido, y a cada sentido un límite articulador del mundo, entonces el sentido acaba allí donde la comprensión deja de ser común. Por eso Carl Schmitt considera tan importante la homogeneidad de la comunión. A resultas de ella, lo que se comparte no es una cualidad u otra, una etnia, una nación, un credo,

$21 C f$. L. Strauss, «Anmerkungen zu Carl Schmitt, Der Begriff des Politischen», en Heinrich Meier, Carl Schmitt, Leo Strauss und «Der Begriff des Politischen».Zu einem Dialog unter Abwesenden. Stutggart-Weimar: Metzler, 1998, p. 104.

$22 C f$. M. Heidegger, op. cit, p.151. 
una cultura, sino, antes que todo eso, una comprensión. ${ }^{23}$ Precisamente por esto, quienes están más acá de la comprensión común, quienes están integrados en ella, son los amigos, mientras quienes quedan más allá de este límite son los enemigos. A partir de la comprensión, de sus márgenes, se fraguan, en definitiva, los límites de la comunidad: los amigos y los enemigos. Pues bien, Schmitt clausura con ello la comunidad; la cierra, concibiéndola en virtud de una determinación cualquiera. Cuando este límite, dispuesto hacia fuera, se pone en cuestión hacia dentro, la que se desfigura, quedando en suspenso, es la misma comunidad de sentido. ${ }^{24}$ Luego, a cada determinación le es intrínseca la posibilidad de la guerra, la posibilidad de un límite que se abre o cierre radicalmente, alcanzando la máxima intensidad, aquella propia de la muerte inminente. Por consiguiente, Schmitt puede considerar que, políticamente, no hay un uni, sino un pluriverso. ${ }^{25}$

Así pues, no habría según él ninguna comunidad vinculante, ningún criterio, ningún único sentido ni, por tanto, ningún mundo común posible. No hay un mundo, hay mundos. $\mathrm{O}$, en otras palabras, como lo que configura las relaciones entre los hombres es la disposición de límites, y como no puede haber uno común, no puede consagrarse tampoco ningún margen de comprensión compartido. Así, lo común no es más que la intensidad de lo posible, concretado como determinación, como decisión, como realización suya, lo cual sugiere siempre la radicalización de su intensidad decidora, a saber, hasta el límite último de la finitud. Como lo conflictivo o lo polémico no es, pues, que pertenezca a una mera posibilidad entre varias, sino que es esencial a todas ellas, dada la constante disposición de los límites, Schmitt puede concluir que quien renuncia a ella, lo que hace en verdad es abandonarse a su heteronomía. ${ }^{26}$ Quien lo dispone, lo

23 Consecuentemente, y ya en sus tempranos escritos, por ejemplo en el sobre la visibilidad de la iglesia, insiste en la importancia de una cierta homogeneidad, dado que ella asegura la consustancial comunión en la comprensión y, de este modo, que el poder supremo pueda provenir desde el derecho, es decir, que el Estado sea en el derecho. Cf. C. Schmitt, Tagebuch, Die Militärzeit 1915 bis 1919. Berlín: Akademie, 2005, en especial, p. 448, así como Der Wert des Staates und die Bedutung des Einzelnen. Berlín: Duncker \& Humblot, 2004, p. 52, y Staat, Grossraum, Nomos. Berlín: Duncker \& Humblot, 1995, p. 49.

24 Con esto se relaciona el que, según el propio Schmitt, la peligrosidad de los hombres, nunca pueda verse amenazada, pues lo amenazado con ello es lo político mismo. A resultas de esta peligrosidad, una comunidad, o un individuo incluso, en la medida en que es peligroso, se salva del peligro, o sea de la muerte, mediante el mismo peligro, cuestión que Strauss identifica con la aprobación de la fuerza y, en suma, con la necesidad de dominio. $C f$. L. Strauss, loc. cit., pp.114-115.

25 Cf. C. Schmitt, Begriff, op. cit., p. 54.

26 A resultas de esto, siguiendo a Heráclito, él anota que unos devienen señores y otros esclavos. Cf. C. Schmitt, Glossarium. Berlín: Duncker \& Humblot, 1991, p. 204. 
que hace, en cambio, es decidirlo, a saber, con una intensidad que puede ser, esencialmente, total.

Ahora bien, él no considera nunca el contenido de la decisión, sólo sugiere que ha de haber una. ${ }^{27}$ Con ello, es decir, con la decisión cuya intensidad se afirma o dispone, se totaliza el sentido, el horizonte desde el cual los hechos se vuelven comprensibles. De esto se trata, y no de la simple confrontación. Cómo vivir, más que si se ha de vivir, es lo que queda en el núcleo. ${ }^{28}$ Con la intensificación de la decisión, lo que está siempre en juego es, entonces, este límite último, es decir, la posibilidad de la guerra llamada a definirlo, y esto quiere decir, la muerte. A pesar de ello, lo que evita la radicalización del sentido, al menos hacia dentro, es, según Schmitt, la proporcional homogeneidad de esa unidad cerrada que representa la mayor intensidad de toda agrupación: el Estado. ${ }^{29}$ Aquello que configura el Estado no es, por esto mismo, una mera norma o un conjunto de ellas, sino el orden. ${ }^{30}$ Nada sorprendente, pues, la preocupación de Schmitt por el nomos. A él, por cierto, no le importa el modo en que se entiende este término tardíamente, como ley, sino su comprensión originaria, que rebasa la ley, llegando al uso, la procedencia, el orden humano y divino, el modo de vida. ${ }^{31}$ Así se llega a la cuestión siguiente. Si no hay una

27 Löwith, en un ensayo titulado «Der okkasionelle Dezisionismus von C. Schmitt», afirma que el contenido de la decisión mentada por Schmitt es por eso, en rigor, casual, y en este sentido dependiente de una occasio política (parodiando la crítica de Schmitt al romanticismo), caracterizando al suyo como un decisionismo ocasional, constituido por una decisión de la decisionabilidad. Cf. K. Löwith, Sämtliche Schriften, 8. Stuttgart: Metzler, 1984, p. 40 y 44. Žižek, por su parte, critica de modo similar la inversión de Schmitt, de un formalismo normativo en uno decisionista. $C f$. S. Žižek, «Carl Schmitt in the age of post-politics», en Ch. Mouffe (ed.), The challenge of Carl Schmitt. Nueva York-Londres: Verso, 1999, p. 19.

28 Así lo considera en un breve trabajo, al analizar la guerra y la lucha. $C f$. C. Schmitt, Staat, op. cit., p. 137.

29 Schmitt llama Estado a la unidad más intensa. $C f$. C. Schmitt, «Staatsethik und pluralistischer Staat», Kant-Studien, XXXV (1930), p. 36-37. Siendo así, el Estado monopoliza lo político. No obstante, advierte él, el Estado carece de sustancia, de contenido. En la medida en que congrega a un grupo capaz de decidir respecto a otro grupo, considerado por ello enemigo, él es el soberano, vale decir, puede interrumpir por eso la política, a saber, mediante la disposición de una decisión intensa. Con más detalle, $c f$. C. Meier, «Zu Carl Schmitts Begriffbildung - das Politische und der Nomos», en H. Quaritsch (ed.), Complexio Oppositorum. Über Carl Schmitt. Berlín: Duncker \& Humblot, 1988, p. 539; asimismo: M. Moazzam-Doulat, «Future impossible. Carl Schmitt, Jacques Derrida, and the problem of political messianism», Philosophy today, 52:1 (2008), p. 76 y T. Bedorf, «Bodenlos. Der Kampf um den Sinn im Politischen», Deutsche Zeitschrift für Philosophie, 55 (2007), p. 707.

$30 C f$. K. Löwith, op. cit., p. 60.

31 Cf. C. Schmitt, Der Nomos der Erde im Völkerrecht des Jus publicum europaeum. Colonia: Greven, 1950, pp. 38 ss. Aquí él se concentra en lo, según él, más original de este término: la toma de la tierra, aunando orden y territorio. A este respecto, y pese a lo considerado por 
comunidad determinada que sea común, ni parece poder haberla, ¿hay alguna que, no obstante, pueda ser compartida?

\section{COMUNIDAD INNOMBRABLE}

Una comunidad como la sugerida la concibe Derrida, a saber, de la misma manera que Wittgenstein lo más allá del mundo: en relación con lo místico, que Derrida desarrolla como el silencio encerrado en la estructura violenta del orden, asumido, por supuesto, que en esta comunidad hay derecho y, por lo tanto, fuerza. ${ }^{32}$ Ahora, con lo místico, ni Wittgenstein ni Derrida aluden a nada misterioso e inaccesible, sino a este quedar atrás de los hechos constitutivos del mundo, del derecho y de la fuerza o, se puede agregar incluso, de los nombres (que ciertamente tampoco son otros hechos). ${ }^{33}$. Con ello ninguno de estos autores está mentando un sustrato o un fundamento, sino sencillamente lo innombrable o indisponible. Pero, entonces: ¿cómo puede decirse una comunidad sin decirse, asumido que lo propio de ella es una determinación, es decir, el que ella se configure como esta o la otra?

Aquí se precisa volver a lo esencial de toda agrupación. Quienes se reúnen, no lo hacen, en primer lugar, ni por amor, ni por odio. Que uno sea con los demás, que co-sea con ellos, se debe a lo que constituye esta relación: la reunión contingente de vecinos o, en una ciudad, de ciudadanos. Ya se ha advertido que politikhe alude a la ciudad sólo en un momento posterior, como, por lo demás, se advierte, a propósito suyo, en las referencias de Platón al alma, y en las de Aristóteles a lo común o, en este sentido, general (to kathólou). ${ }^{34}$ Pues bien, a esta reunión configuradora del conjunto, dada la finitud de los miembros que la componen, le es propia la relación recíproca de sus miembros y el que, en virtud de ello, haya una distinción entre los mismos, dada la consustancialidad del límite en toda relación finita. No es, entonces, que con el constitutivo distinguirse se diluya la comunidad, sino más bien que esta reunión en que ella

Schmitt, cf.C. Meier, Die Entstehung des Politischen bei den Griechen.Frankfurt/M: Suhrkamp, 1995, p. 305 ss.

32 Que exista silencio en su estructura, quiere decir que la violencia y el derecho se constituyen por referencia a sí mismos, y que, por tanto, se trata «de una violencia sin fundamento». Cf. J. Derrida, Force, op. cit., pp. 33-34.

33 Aunque no lo llama místico, Benjamin, por su parte, piensa en algo similar cuando se refiere al lenguaje. Con la relación absoluta propia del nombre que llega a conocerse a sí mismo, lo mentado es Dios. Él es idéntico a la palabra creada, por consiguiente, no hay en él mediación, sino él es «el medio puro del conocimiento». $C f$. W. Benjamín, op. cit. p. 39.

34 Aquello que se refiere al alma es, dice Platón, la política. Cf. Platón, Gorgias. Madrid: Gredos, 2000, 464b. Aristóteles, por su parte, enfatiza la distinción entre lo individual y lo general, advirtiendo que el objeto de las ciencias es esto último. Cf. Aristóteles, Ética a Nicómaco. Madrid: CEPC, 1999, 1180b. 
consiste se configura a través de este estarse distinguiendo, es decir: hay reunión porque hay distinción. $\mathrm{O}$, dicho de otro modo, aquello en lo que consiste esta comunidad en permanente distinción, lo esencial de la misma, es la contradictoria vecindad de sus miembros. A esta contrariedad apunta Derrida con este término: philopolemología. ${ }^{35}$

A su vez, este intrínseco distinguirse tiene lugar por medio del lenguaje. Con lo cual, aquello que constituye al lenguaje es esta reunión de lo distinto. Así se entiende que para Heidegger pólemos y lógos sean lo mismo. ${ }^{36}$ Aquello que acontece, que está en constante movimiento, es entonces este estarse distinguiendo, y a ello, realizado como lenguaje, en la medida en que tiene lugar, es a lo que se refiere la historia. Remitida esta dinámica a un horizonte que la vuelva comprensible es que se llega al sentido, que no refiere entonces nada previo, ni más allá, ni tampoco un fundamento, sino la comprensión conjunta del mismo movimiento. Con ello, lo propio de esta comunidad es la apertura constante de su comprensión, y no el cierre que, por contra, la acota. Con su acotación se consuma una posibilidad, una comprensión en virtud de la cual la apertura se llena de contenido. A lo religioso, por ejemplo, le es propio precisamente esto último, el contenido, en cuyo conocimiento se realiza la unidad de una comunidad, conocimiento que, en esta misma medida, se cultiva. ${ }^{37} \mathrm{~A}$ cada contenido de tal comunidad le es propia una realización común que, por mor de sí, se cierra, es decir, se comprende de un modo u otro, encontrando en el contenido el horizonte desde el que ella misma se vuelve comprensible.

Una comunidad reunida, en cambio, no por el contenido, sino por la apertura del mismo, cualquiera que sea; una comunidad, por consiguiente, sin contenido, ${ }^{38}$ es aquella en la que lo entre de las relaciones humanas ocurre sin ninguna referencia, sin ninguna mediación más que la suya. A esto se refiere el que sea sin nombre. Pero, si no el contenido, ni el nombre de la misma, ¿qué

35 Cf. J. Derrida, Politiques, op. cit., p. 343 ss.

36 Cf. M. Heidegger, Einführung in die Metaphysik. Tübingen: Max Niemeyer, 1966, p. 47.

37 Con lo cual, el contenido, o la comunidad que se llena del mismo, y el correspondiente conocimiento de lo vinculante, coinciden. Así se aúnan en el quehacer lo propiamente vinculante (religio) con su contemplación (sapientia). Agustín, acaso paradigmáticamente, desarrolla esto en numerosas obras, por de pronto en su De vera Religione, aunque también en su Civitas Dei y, en no menor medida, en su De Trinitate. Al respecto, en lo que aquí concierne, $c f$. M. Maureira, «Scientia y sapientia. Anotaciones conceptuales al agustino De Trinitate», Diadokhe, 9: 1-2 (2006), pp.47-63.

38 A esto se refieren Nancy con su comunidad desobrada, Blanchot con la comunidad inconfesable y Agamben con la comunidad que viene. Cf. J.-L. Nancy, La communauté desouvre. París: Christian Bourgeois, 1990; M. Blanchot, La communauté inavouable. París: Éditions de Minuit, 1983; y G. Agamben, La communità che viene. Turín: Einaudi, 1990. 
vincula a los hombres en esta comunidad? Propiamente el quehacer puro, la interacción que él supone; él es el espacio en el que se constituye su apertura. El mundo consiste en esto. Aquí cada uno converge distinguiéndose. Con la revelación que se nos da del conjunto, lo que se revela entonces no es más que una figura del mismo, es decir, una forma de lo posible. A este quehacer que acontece en un horizonte, en el que se consagra una posible comprensión, le es propia, por cierto, la negación de toda otra, por cuanto lo constitutivo suyo es la diferencia, la constante distinción de lo finito. Con esta distinción, resultado del quehacer, lo que se esencia no es sino la mediación de la comprensión, que, realizada conjuntamente, da lugar a una actualización común. ${ }^{39}$ Porque, sin embargo, lo que constituye el mundo no es ninguna figura determinada, ningún nombre, no hay uno común, ni ningún contenido que lo sea. Por consiguiente, no hay tampoco ningún fin universal, pues el quehacer conjunto no es ninguna poiesis, sino una praxis, a la cual le es propia también la indefinibilidad de un fin. ${ }^{40} \mathrm{~A}$ resultas de no vincular ningún contenido, Schmitt puede acentuar, pues, la distinción que se da con la decisión más intensa, cuya implicancia no es otra que la negación de lo no comprendido por ella. Así, a través del enemigo, lo que se exalta es el límite de una comunidad, que da unidad a quienes la comparten, representando esta última, por antonomasia, el Estado, cuya unidad supone una identidad compartida, que Schmitt, sin embargo, nunca define, pues aquello que configura lo político, al fin y al cabo, no es más que el distinguirse, no éste o aquél otro, sino el distinguir mismo, el constante estarse distinguiendo. Aquí encuentra su lugar el sentido, en la medida en que en toda distinción queda atrás ella misma, escondida en lo distinguido. Con lo distinguido se trae a la presencia una distinción, se consuma una posibilidad de la misma, dejándose ausente la posible sin más.

Que los hombres se agrupen en función de una figura, que este agrupamiento tenga lugar por medio del verbal distinguirse, le da performativamente forma a lo distinguido. Así pues, bien visto, lo insinuado por Schmitt no es la aniquilación del enemigo, sino sólo su negación, lo cual quiere decir: distinguirse de él

39 Concretándose así, históricamente, la existencia. Conforme a esto, Estado querría decir el «ser histórico de un pueblo». Cf. M. Heidegger, Logik als Frage nach dem Wesen der Sprache. Frankfurt/M: Vittorio Klostermann, 1998, p. 165.

$40 C f$. Spaemann, Robert, «Aufhalter und letztes Gefecht», en K. Stierle y R. Warning (ed.), Das Ende. Figuren einer Denkform. Múnich: Fink, 1996, pp. 564-577. Aunque carezca de fin, la praxis puede tener un sentido, si se considera la vida lo esencial de la misma. Schmitt, pese a no determinar tal sentido, lo relaciona siempre con la posibilidad de la muerte física. $C f$. C. Schmitt, Carl, Begriff, op. cit., p. 33. Al respecto, véase además $C f$. R. Rother, Wie die Entscheidung lesen? Zu Platon, Heidegger und Carl Schmitt. Viena: Turia \& Kant, 1993, p. 80, así como C. Hermes, Politik und Transzendenz. Ordnungsdenken bei Carl Schmitt und Eric Voegelin. Berlín, Duncker \& Humblot, 2009, pp. 59ss. 
con una cierta intensidad. ${ }^{41}$ En esta individuación, antes que una división, está en juego el quehacer del hombre que, a su vez, más que la figura, constituye el estarse dando este quehacer, es decir, el mundo, cuya comprensión rebasa los límites de una determinación, pues con su apertura no es ella lo que se mienta, sino el innombrable horizonte de su posibilidad. A esta comunidad en la que no hay contenidos comunes, en la que cada uno, puesto en relación con los demás, asume todas las distinciones que tal movimiento supone, dado que lo que ata es el movimiento mismo, le es propio no dejarse decir, sino ser el medio del decir puro. Con este despliegue se corresponde el sentido, que no queda, en suma, ni más allá ni más acá del mundo, sino que constituye la existencia misma de tal comunidad, su abierta posibilidad, que, al realizarse, se presenta escondiéndose precisamente como sentido.

MAX MAUREIRA pertenece al Centro de Filosofía Clásica Alemana (Argentina)

Publicaciones recientes:

(2010) Ethnos-Ethos-Estado, Buenos Aires: Editorial Biblos.

(2011) «Das rechtliche Geflecht. Zur Intersubjektivität bei Fichte», Stuttgart.

Líneas de investigación:

Idealismo alemán, metafísica, filosofía del derecho, filosofía política

Dirección electrónica: Max.Maureira@uv.es

41 Quién, por ello, sea concretamente el enemigo, es completamente indiferente, lo esencial es la negación implicada en cada decisión que, dispuesta, lo configura. $C f$. B. Radloff, «Heidegger and Carl Schmitt: the historicity of the political (part one)», Heidegger-Studien, 20 (1994), p. 86. 